\title{
Resposta à carta ao editor "Qual a melhor opção: desenvolver questionários nacionais ou traduzir e validar questionários internacionais?" sobre o artigo "Adaptação e validação de um questionário sobre comportamentos de risco para Aids em usuários de droga em Porto Alegre"
}

Em resposta à correspondência de Malbergier, gostaríamos de discutir alguns pontos relevantes:

1. Qual a melhor opção: desenvolver questionários nacionais, mais adaptados à cultura brasileira, ou adaptar questionários internacionais? Isto se relaciona ao tema específico de pesquisa. Evidentemente, comportamentos de risco brasileiros são diferentes de comportamentos de risco americanos (o que fica claro quando discutimos a supressão incorreta de toda uma seção do CRA nas suas primeiras versões brasileiras), ${ }^{1}$ sugerindo uma definição específica para uso regional de instrumentos. Entretanto, perde-se quanto à possibilidade de estudos comparados, multicêntricos, objetivo específico do projeto ao qual este questionário se vincula.

2. Alguns estudos [brasileiros] já utilizaram questionários para avaliar comportamentos de risco em usuários injetáveis. Os autores desconheciam o instrumento da OMS citado por Malbergier e publicado em 1993 no Bulletin of Narcotics, motivo pelo qual não foi avaliado para utilização no projeto de pesquisa. Quanto ao outro instrumento, que consideramos de boa qualidade e que foi mencionado em nosso artigo, acreditamos que sua utilização seja posterior ao início de nosso estudo, tendo-se iniciado o processo de validação do CRA em 1994, data do financiamento do primeiro projeto de pesquisa. Mesmo assim, a carência de material utilizável em língua portuguesa reacende a questão sobre a pobreza de material específico sobre o tema em nosso meio, em qualquer idioma.
3. Quanto à necessidade de validação concorrente versus confiabilidade do relato: Este é um ponto sensível no que concerne à validade das informações obtidas por usuários de drogas, e concordamos quanto à falta de um estudo de confiabilidade teste-reteste, que já se encontra em preparação por nosso grupo. À afirmação sobre a dúvida quanto à confiabilidade de informações, contra-argumentamos com uma afirmação de Inciardi, em projeto de pesquisa encaminhado ao National Institute on Drug Abuse (NIDA), ${ }^{2}$ que sustenta que "(...) grande quantidade de estudos controlados foi conduzida ao longo dos anos documentando que, quando questionados sobre seu uso de drogas e atividade sexual em um ambiente não ameaçador, usuários de drogas e outros indivíduos expostos a risco fornecem informação confiável." Mais recentemente, estudos de campo realizados em Miami, San Francisco, Houston, Detroit e Denver, dentro do Acordo Cooperativo do NIDA, confirmaram que usuários de drogas recrutados na rua e devidamente informados do processo de pesquisa, tendo sido reembolsados pelo tempo gasto nas entrevistas, responderam de forma consistente e confiável a questões sobre seu uso de drogas e práticas e experiências sexuais". 3

Flavio Pechansky pelos autores

\section{Referências}

1. Pechansky F, Soibelman M, Kohlrausch E. Assessment of risk situations for HIV transmission among drug abusers in Porto Alegre, Brazil. J Drug Issues 1997;27:147-54.

2. Inciardi J, Surratt H, Pechansky F. HIV Prevention among women sex partners of drug injectors in Brazil. Projeto de pesquisa submetido ao National Institute on Drug Abuse em fevereiro de 2002.

3. Needle R, Weatherby NL, Brown BS, Booth R, Williams ML, Watters JK, et al. The reliability of self-reported HIV risk behaviors of injection and non-injection drug users. Psychol Addic Behavior 1995;9:242-50. 